\title{
DEUKI PRATHA IN NEPAL: PROBLEMS AND CHANGING BELIEFS
}

\author{
Dipendra Bahadur K.C. \\ Lecturer, Department of Social Work, Padmakanya Multiple Campus, Kathmandu, TU. \\ Corresponding aurthor: kcdipendra18@gmail.com
}

\begin{abstract}
In the far-western region of Nepal, particularly, in Doti, Baitadi and Dadeldhura, deuki pratha has been practiced as a long established tradition. However, Deuki pratha is considered illegal in Nepal. Deukis are offered to different deities by parents or others (wealthier couples). The reason behind deuki pratha rests on the belief that one's family gets protection and good favour from the gods. Once offered as Deuki, the girl is not allowed to get married and is devoid of the family support. The major duty of Deuki is to serve the goddess and temple such as cleaning and looking after the temple.
\end{abstract}

The study was conducted in Melauli Municipality of Baitadi district in Sudurpaschim province. This paper aims to highlight the social issues due to deuki in the study area. The study aimed to understand the socio-cultural beliefs of deuki tradition in the changing social and cultural contexts from the gender perspective and development.

The study was based primarily on qualitative methods. The study revealed that deuki tradition is still practiced, though it is reported to be declined in the recent years. Unlike in the past, with the growing awareness by the joint efforts of government and non-government organizations' agencies, practice of Deuki has declined to a great extent but not abolished yet. There was mixed reaction regarding beliefs upon Deuki tradition among the locals.

The study found that Deuki women who had been offered to the deity was unknowingly been isolated, when still as a girl and abused from the society as these came at the cost of personal and social life of women. With the growing awareness, and changing society, the locals and the followers of deuki pratha seem to welcome the changes and attitudes towards deuki pratha. However, the social and economic life styles of deukis are at stake. Though, some deukis own some private property, due to the lack of emotional and social support are bound to live forbidden and 
isolated life. Unlike, in the past, where deukis received reverence and importance, the perception towards deukis has worsened in the study area often belittled as prostitution and the disgrace to the society.

Keywords: jaant - gods and goddesses - human rights - stigma and discrimination - public harassment - belief system - isolation.

\section{INTRODUCTION}

In the course of human history and civilizations, several social and cultural practices have developed which have their roots in the fulfillment of their wishes or protection from unknown forces. One of the manifestations of such practices is slavery and attempts to appease Gods and Goddesses by making expensive offerings, sometimes even human beings. Deuki tradition is one of the prominent examples of human as offerings to appease the God for the protection and good happenings in the future.

Deuki pratha is a socio-religious tradition practiced in districts like; Baitadi, Dadeldhura, Doti in the far-western region of Nepal, where a young girl is offered to the local temple to get good blessing and protection from the god. Deukis are offered to different deities by parents or wealthier couples (Stark \& Rebecca 2004). The reason behind Deuki pratha rests on the belief that one's family gets protection and good favour from the gods. Once offered as Deuki, the girl is not allowed to get married and is devoid of the family support. The major duty of Deuki is to serve the goddess and temple such as cleaning and looking after the temple.

The Deuki pratha that started in the far western parts of Nepal is believed to have been started by the King Naga Malla in the $14^{\text {th }}$ century (Ghimire 1976, Prince 2019) in order to ensure his family and to consolidate his powers by seeking blessings of the deities by appeasing them. In the course of time, the practice started to be followed by the people in the region. Whenever they had to ask for anything from the deity, they would vow to offer a Deuki to the deity. Thus the number of such Deukis offered in the temple kept growing who would take care of the temple and assist in the worship related activities of the temple. They were not allowed to marry and live a settled life. However, people could have physical relations with them and the children born of such out-of-wedlock relations also would become Deuki (in case she was a girl) and Deuka (if he was a boy). The tradition started to give rise to some social and family problems in the regions where the tradition was in practice. There have been attempts to abolish the system by the government by making law and arranging provision for their 
rehabilitation. Even though, the practice is a dying tradition, the impact that it has created in the society is still in existence. Since, Deuki has been prohibited by the Constitution of the Kingdom of Nepal- 1990, several efforts has been made by government and non-government organizations to discourage it. Therefore, there is a clear need to fully understand the present situation of the Deuki pratha in the changing scenario. It is also equally important to understand the various consequences and impacts of this socio-cultural phenomenon.

This article explored various facets of Deuki pratha, its influence in the society and various measures taken to address the issue and recommend future course of action to mitigate the effects of the tradition in the society and the ways how best issues of deuki can be managed

\section{STATEMENT OF THE PROBLEM}

Deuki pratha has been considered as a social evil and is subject to legal offense anybody who forces it happen. Following the ban in Deuki pratha, this traditional practice is rarely seen in recent years in Nepal (AntiSlavery Society 2003, Yogi 2012)

Unlike in the past, with the growing awareness by the joint efforts of government and non-government organizations agencies, practice of Deuki has declined to a great extent but not abolished yet. With this changing scenario, this article tries to understand about socio-cultural beliefs of the Deuki pratha among the locals. How Deuki herself understand this system? How do the Devotees and experts in the society take this tradition?

The Deuki pratha that started in the past as a result of some specific instance has continued to plague the society. Even though, it had started with good intention and in agreement of the people concerned, in the course of time the practice has become like a rigid tradition that the society is not easily able to break away from. A critical and academic look and indepth study and informed analysis is required to the issue of Deuki pratha practiced in the relatively less economically developed far western region of Nepal.

In the Far-western province of far western region, Nepal, Deukis are offered as virgin girls to the deity's temples by devotees to fulfill one's wishes from the deity. The present study aims to explore the problems posed by Deuki pratha and provide recommendations to policy level. 
Previous studies on Deuki system have been conducted focusing on religious aspect (Wanta 1992, Gautam 1993, Adhikar 2014, Budha Air 2009) and cultural aspects (Shrestha 2001, Ghimire 1976, Bista 2008, Subedi 1991). But the attitudes towards deuki as a tradition and deuki as an individual have changed over the course the time. The traditional status of deuki and the growing concerns towards their identity has raised serious concerns. The legal ban on deuki pratha clearly indicates misinterpretation and misconduct of deuki pratha. The problems faced by deukis in course of rehabilitation and its effects at individual and societal level has been considered the research problem. So, the study attempted to fulfill the following objectives;

a. To analyze socio-cultural beliefs about Deukis in the present

b. To assess problems posed and faced by Deukis in the society

c. To recommend future course of action to mitigate the effects of Deuki pratha in the society

\section{Conceptual framework}

The Practice of Deuki System is listed with the complex phenomena of the Society and culture of the research consideration. The Deuki system cannot be understood in an isolated form. The root of the practices is deeply limited to its history, culture, society, religion and economy. This demands a holistic analysis of the Deuki system in order to make the research work more valid and reliable in its structure, function and meaning system. Thus Deuki practices are influence by social, cultural and psychological factors here (Figure 1).

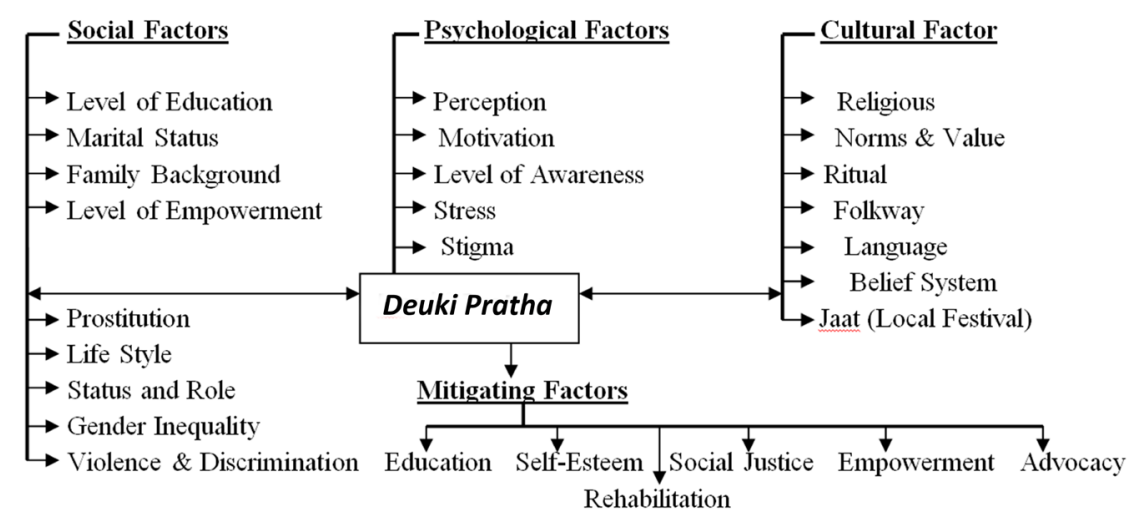

Figure 1: Conceptual framework 


\section{LITERATURE REVIEW}

The seats of civilizations like Rome, Portugal, Spain, Great Britain and Ireland had slaves working in the temples and had female dancers in most of the places of worships that extended to different parts of the world including India where the influence of such practice was high in the states of South India, Bengal, Assam and Maharastra (Joshi 2066). In the course of time, in order to please the Gods, the devotees started offering riches, jewelry bedecked clothes and also young girls who were referred to as devdasi and their job was to cleanse the temple, make arrangement for worship rituals, welcome the devotees and sing and dance in the temple (Mishra 2001). The practice of devdasi existed in Hebrew-Jewish tradition, Babylon and the regions around it, Egypt, Phynisia and Syria, Iran and neighbouring regions, in China, Yunan, Rome, Italy, Spain, Portugal, Algeria, Germany and neighbouring regions, Russia, different regions of Africa and Indian Subcontinent (Desai 1989). Likewise, devdasi tradition was in vogue in South India, Central India, Eastern India, Western India, Northern India and Nepal (Desai 1989). In Nepal, the tradition has been called deuki and is believed to have been started by King Nag Malla of Doti Kingdom who ruled from 1384 to 1400 who was very powerful and strong and dared even Gods but is believed to have been defeated in challenges to the deities of the region and also being childless, is believed to have offered a virgin girl to the local deities and is believed to have been blessed with a son and the tradition of offering a girl called Deuki to fulfil the wishes is believed to have started since then (Ghimire 1976). Even though it has the features of slavery system, unlike the common slavery system, Deuki tradition is regarded as 'respectable' (K. C. 2013). The tradition also had negative consequences in the society, so much so that some people who had established relationship with Deuki started supporting them in clandestine manner, sometime causing economic and marital hardship in the family (Yatri 1976). Considering such consequences and with Deukis themselves facing troubles in their livelihood and sustenance, the then local ruler Deep Chand Thakuri started the movement to solve this problems arising out of this system (Ghimire 1976). In the modern Nepal, all forms of slavery have been abolished and government has made provisions for their release and sustenance (K. C. 2013).

According to Prince (2014), Deuki is deprived of many rights like marriage, education, etc. It is believed that sexual relationship with Deuki can lead to religious advantages. So Deukis are physically exploited by 
priests and worshippers. Though the country code of Nepal 2020 BS has clearly banned prostitution on the basis of any custom and tradition, this system is still alive in the society. Illegal children born from Deuki hardly can get citizenship. Deuki pratha has been formally eradicated by the government of Nepal. However, there is still sign of this custom in western and far western development region of Nepal.

Deuki is an ancient custom practiced in the far western regions of Nepal in which a young girl is offered to the local Hindu temple to gain religious merit. Young girls are offered by poor families. Also, another cause is the false belief of gaining protection and good favor from God. Deukis have to depend on worshipers' monetary offerings to the temple for their livelihood. Left with insufficient income, no skills or education, and pressure brought on by the conviction that sex with a Deuki can cleanse sins and bring good luck, many Deukis are driven to survival sex, a form of prostitution in which sex is traded for basic necessities such as food or shelter. Though it has been formally abolished by the constitution of Nepal, 1990, it has not yet been abolished completely (Yogi 2012).

Kathayat (2014) documented that although deukis strongly follow traditional culture, they bear children without marriage. Deuki are being offered from the family belonging to touchable status and also by devotees none other than her own family. Once offered, the surname (caste) of the father does not exist and she becomes Deuki, a different caste and status. Deukis are virgin girls offered to the deity by devotees.

Shahi (2003) reported that Deuki, particularly the young girls who are dedicated to the temple by the devotees are prohibited from leading normal lives, who started to practice prostitution. Deuki girls began being used for sexual activities and with the shamans, storekeepers, the priest of the temples and other people. By these activities Deukis were financially supported and Deukis were no longer considered pure and the Deuki system changed into prostitution. Deuki girls used to start prostitution as soon as they reached puberty stage. The Deuki clients could be the touchable local people and even non touchable in secret. The local people say the Deuki are unsprinkled touchable, which means that people do not sprinkle water after touching them. This means the Deuki keep sexual relationship also with untouchables.

Previous study lack issue of rehabilitation (normal life) of Deuki which is one important research gap. From the careful perusal of 
literature, reveals that much of the study on deuki have been descriptive. These studies have focused on religious and cultural aspects of deuki as tradition and few studies have attempted to explore the attitudes of society towards deuki pratha and deuki herself. However, the problems posed by and consequences to individual and society by deuki pratha is still scanty. Moreover, the ways to mitigate deuki pratha in changing context has been least explored.

\section{METHODOLOGY}

The study was based on qualitative methods. The study adopted the case study methods that comprised the Key Informant Interview (KII), Focus Group Discussion, observation, interview, folklore analysis were used to ascertain primary data whereas secondary data were collected from different published and unpublished literatures. The study extended for a period of six months (12 ${ }^{\text {th }}$ March 2019 to $16^{\text {th }}$ Sept, 2019) with frequent field visits. The study was based on multi-stage sampling. The first stage of sampling used to select the study region was purely purposive, followed by simple random sampling to select the rural municipality and/ or municipality and finally the sample unit; Deukis were selected through snowball purposive sampling method. A total of 12 Deukis were sampled. So, 12 Deukis were interviewed and observed under the case study.

\section{RESULTS AND DISCUSSION}

\section{Changing context and the socio-cultural beliefs towards Deuki pratha}

The mixed reaction was captured regarding the socio-cultural beliefs on Deuki Pratha. The KII with Deuki herself, experts and Chief Devotees reflected that the beliefs on Deuki still persisted and however is declining in recent decades.

The respondents believed that the faith rooted in the society and devotion to the deity had attracted many families to offer girls as Deuki. According to Deukis, if they follow the norms strictly as Deuki, they held the beliefs that she lives in peace, good life and her next life will be good. If they violate the norms prescribed for a Deuki then it is the belief that they will be punished by god. On the basis of experiences by the deukis themselves, they shared that there are plenty of challenges than opportunities for becoming Deukis. Respondent also shared that there is a wrong belief that Deuki doesn't have to bear any worldly responsibilities, and assume that Deukis lead a life of independence, happiness and pleasure. 
But in contrary, deukis are forced to become and gets only basic protection like food, clothes and shelters according to respondents. Respondents also believe that Deuki pratha is against human rights.

The Deukis admit that the perception of society towards them has changed from reverence to hatred. The moral, religious and cultural importance of deuki pratha has been worsened. However, at deukis'level, they had deeper faith on the deuki tradition that the deity protects and fulfill the wish of the person who offered the deuki used to be invited by the followers of her deity on the occasion of marriage, bratabandha, saptah, nawah, special festivals, house warming etc. They used to be welcomed by offering donations and honor. However, Deukis could not expect gifts like pote, tika, sindur, gajal etc. that reflects the marital signs. Moreover, the last rites of Deuki used to be respectfully conducted by the person who offered her to deity and her relatives and 'Jutho' (food that is being eaten by others and one is not supposed to take it for health and cultural reasons) is caused to relatives and her family members. She is also affected by juthosutak (cultural ritual where one has to avoid activities such as worldly pleasures, eating food outside other than the home) if her family members die. During the special pujas (worshipping ceremony where usually the priest conducts), Deukis are offered with money, food grains, ghee, oil, material goods, clothes etc by the management committee of the respective 'mandou' (temple). Deukis used to be invited in feast organized on the washing/bathing celebration of the deity and her roles are cooking food, washing the dishes and welcoming the chief of the temple.

With the growing hatred and humiliation in the society, the Deukis had started to feel that the deity did not posses them. Deukis expressed that the prohibition of legal marriage and complete devotion to the service of God had nothing to offer them rather just trauma, hardships, devoid of basic human and women rights.

Deukis are generally illiterate and are unskilled and they don't get any facility from state, social organization or local government. There are generally various socio-cultural issues Deuki had faces like violence, discrimination, evil practices of culture, injustice and abuse. And the solution according to the respondent may be employment, awareness and advocacy.

The KII with experts related to Deuki pratha revealed that girls belonging to Brahmin and Kshyatriya caste in particular are made Deukis. 
If a Deuki has children, then generally they are isolated in the society and nobody marries them and lacks education. This case though insignificant in recent years, was rigid until 1990, when the Constitution of the kingdom of Nepal 1990 and 2015 formally abolished the Deuki practice. So far, attraction towards Deuki pratha is concerned, there is not any attractive offer for becoming Deuki but parents offer them due to reasons such as to have better fortune and health of family members and sell their own child to others due to poverty. According to them, Deukis are honored on the basis of religious belief and given the place of Devis (Goddess in Hindu religion) but the changing perception towards Deukis by the society and social problems caused by Deuki pratha had divided the society into groups for and against Deuki pratha. Those who stand for Deuki pratha believe that there should be someone to look after their deity, clean the temples, maintain sanitation, conduct pooja etc. But, nowadays this tradition is legally banned and only some incidents of Deuki tradition could be captured in the society according to the experts.

The KII with Head of the Devotees (Priest, Dhami, Bhandari, Chief Priests) revealed that Deukis are categorized into two types as thulajaat (high caste) and sanajaat (low caste) also called paattar. The head of devotees perceive deuki as a holy female purified with holy water. They were of the opinion that perception of society has tended to be negative to any deukis who has given birth to children and therefore isolated them. The heads still have deep faith on deities to whom the deukis were offered and believe that the deities have super natural powers to solve the problems and fulfill wishes of devotees.

The head of devotees shared that even today; particularly in Baitadi district if any elder daughter of a Deuki refused to become Deuki then it is believed that she will not get the place of goddess or devi. The head of devotees also argued that the locals are aware of their basic human and women rights and therefore, reject this tradition.

The Head of Devotees also believed that if some humanitarian reforms are made in Deuki pratha like allowing them to marry and live a settled family life, the tradition may not be considered objectionable then that would be very good for them. Devotee Heads traced out the problems due to Deuki pratha such as psychological impact, physical exploitation of the girl and social and economic isolation. 


\section{Deuki pratha as a problem}

The key informants' interview revealed that with the growing signs of family breakups and disputes due to Deuki tradition, the then local administrator, Dip Chandra Thakuri started the campaign to stop this tradition. In addition, at personal level, Dip Chandra Thakuri and Lakhu Bhaat even supported the Deukis who had faced problem of proper clothing as the offerings and religious gifts from devotees could only meet the needs of food for them. Despite these attempts, the negative attitude and treatment towards Deuki continued (Ghimire 1976).

There had been incidents in the past, when a husband who fell for Deuki provided her with cash, jewelry, clothes, utensils, and even food grains in secret. When the wife came to know about this incident, the couple quarreled and worse enough the husband broke the hand of the wife when she made her parents known about this incident. Unfortunately, such incidents were considered normal in the society in the study area (Yatri 1976, 127-130). So, many of the informants expressed that the berating of Deuki today is linked to their wrong doings such as getting into relationship with male or males and even having children out of relationships. These activities are forbidden and considered wrong for Deukis.

The responses of structured questionnaire and the interviews also reported that the cultural ban on marriage to deuki is the cause of birth of social problems. Just like the married women as they are believed to be married with the deity. Like the normal women, deukis also are allowed to wear colourful clothes, jewelry and sindhoor (vermillion) and pote (a Nepali word for the colorful glass beads which play an important part in Nepalese weddings, worn by women and is a symbol of marriage). Deukis have monopoly over the offerings by devotees and earnings from jaant (a festival celebrated in the Far-western province during the month of Kartik. The animals including he-buffaloes and he-goats are sacrificed and people put on new dresses and eat delicious food, meet family and relatives) and even can sell the property. However, all these facilities is barely enough to keep them happy and secured as they are devoid of the most significant aspect of life i.e. the marriage.

These days, Deuki pratha has been viewed as a symbol of violation against women. The experts and even the devotees opined that in later phase (since the last three decades) the condition and perception towards Deuki changed from pure to impure, reverence to disrespect and from social 
prestige to social outcast. The informants accept that Deuki is an epitome of extreme exploitation and pain over the women and this has formed the basis of women subordination by society. They reported that the followers of this tradition are those who forbid women from the rights to marry and become a mother that nature holds for her. They vehemently rejected Deuki pratha as a tradition and considered it as the most superstitious, ignorant, pompous and stupid act.

Various reasons were attributed for continuity of Deuki pratha. Some respondents accused deukis for misappropriate acts. They charged them for being engaged in prostitution in exchange for money and goods. They blamed them for hampering family relationships. They even blamed Deukis for their misconducts causing the holy religious practices turned into the unholy one. The study showed that the respondents were also aware of the fact that words do not make any man ideal and it is actions that defines the person. The truth might remain unknown for a time being but surely is realized by people one day. The respondents in the study were not open to talk about the present situation of Deuki. This is another reason why Deuki has not yet been abolished from this hard hit are of the far west Nepal.

\section{Mitigation measures to Deuki Pratha}

In the name of tradition, Deuki pratha encompasses many positives than negatives at individual level, the Deuki herself and the societal level. Deuki pratha has been criticized as a social evil that is against humanity and social norms. With the growing awareness led by various government and non government organizations, the Deuki pratha has been in decline. From the field survey and interviews, various suggestions have been collected as measures to end Deuki pratha in the study area. These suggestions include the following;

The continuity of Deuki pratha is attributed to illiteracy, superstition and poverty. Hence, there is utmost need of awareness, employment and access to education and other social benefits as one measure to discourage Deuki pratha in the study area.

Due to social stigma attached to Deuki, they hesitate to open up in the public. Although, the law has been formulated against Deuki pratha as illegal, it is far from being realized in practice and therefore, the role at local level is vital in order to track down Deuki pratha. 
There is need of bottom up approach to mitigation of Deuki pratha. The appropriate ways to bring an end to Deuki pratha requires the local level opinion and actions to be implemented by the policy level.

The deukis are at risk of losing not only their social and economic status but also the health status. This situation demands the rehabilitation of the deukis. For this, the collaborative action would be better.

The deukis are considered outcast in the present society and would end up either in isolation or single. Given the fact, their marriage is a great social concern, the provision of appreciating the one who marries a Deuki is necessary.

\section{CONCLUSIONS}

Deuki Pratha has been a religious tradition practiced in the Farwestern (sudur-paschim) province of Nepal. Although legally banned by the constitution, traces of Deuki pratha are still found indicating the strong influence of the socio-cultural belief of it. The study gathered mixed reactions from the locals in regards to Deuki pratha. The study showed that the Deuki women who had been offered to the deity still as a little girl had been unknowingly isolated and abused from the society and had made Deukis pay the price of their whole life. Deuki has been accused of violating social norms and values. Deuki expressed their feelings of pain and isolation when they were Deuki and had many desires hidden inside them. Various reasons were attributed for continuity of Deuki pratha. Some respondents also accused deukis for misappropriate acts in order to hide their wrong doings and prove themselves good. They even blamed Deukis for their misconducts causing the holy religious practices turned into the unholy one. The in-depth interview with the deukis revealed that it was only the fear and devotion for their deity that had made them struggle for whole life as a Deuki. Experts also took this tradition as being against woman rights. The study reported that with the gradual awareness progrrammes and education in the study area, Chief of devotee (priests, Bhandari, Dhami) had accepted the changes and the perception towards Deuki pratha. They expressed that with the changes in beliefs and practices that comply with the time and situation would help give a way to a dignified status of the Deukis abolished therefore be more acceptable to the present society.

Although it is illegal but still some deep rooted cultural belief had made exceptional practices in the society but the changing structure of the society does not seem to bear such kind of unsuitable practice for 
the modern globalized and technical society. As society changes and the perception towards this kind of culture and tradition. They feel that if such kind of traditions would also be made modified according to the humanitarian needs and according to this structural change of the society then it would be more acceptable to the modern present society of Nepal. Although this kind of tradition had made illegal but it took long time to change the psychology of the people in the society. But still some cases could be heard which shows the remaining fossils giving reflection on the socio cultural belief on this tradition.

\section{REFERENCES}

Adhikari, P. (2014, Sept. 28). A boy offered to the God. Kantipur Daily.

Anti-Slavery Society. (2003). Child hierodulic servitude in India and Nepal. http://anti-slaverysociety.addr.com/hieroras.htm, Accessed: 02.012020)

Bista, D.B. (2008, November, 18). The problems faced by Deuki's. Naya Patrika Daily.

Budha Air, Mohan (2009, July 27). Deuki still in the temples of Baitadi. Kantipur Daily.

Desai, R. B. (1989). Apsara. Varanasi: Hindi Pracharak Sansthan.

Douglas, M. (1969). Natural symbols: Exploration of cosmology. London: Routledge and Kejau Paul, pp. 69-80.

FWLD. (2006). An update of discriminatory laws in Nepal and their impact on women. Forum for women, law and development, Kathmandu.

Gautam, R. (1993, February 23). Where the god needs virgin girls in the place of flower. Gorkha Patra Daily.

Ghimire, T. (1976.). The practice of Deuki system in Melauli Goddess of sacred area in Baitadi district. National Development Service Village profile, p.39.

HMG (1990). Constitution of the Kingdom of Nepal 1990. Kathmandu: His Majesty's Government of Nepal

Joshi, H. (2009). Lok-Ganatantra. Joshi Research Institute, Lalitpur, pp.8485.

K. C. S. (2013). Social and cultural situation of Nepal. Handbook of third Nepali Folklore Congress, Dhangadi- Baitadi: Organising Committee of Third Nepali Folklore Congress, Kathmandu: Nari Development Service, Tribhuvan University, p.512. 
Kathayat, R. B. (2014). Socio-cultural Study of Deuki System in Baitadi District; A case study of Dehi Village of Melauli VDC. (A master's dissertation), Central Department of Sociology/Anthropology, Faculty of Humanities and Social Sciences, Kirtipur.

Mishra, J. S. (2001). Prachin Bharat ka samajik itihas. Patna: Bihar Hindi Granth Academy, pp. 422-423.

Prince, D. (2014, October 8). Amazing history of Deuki Pratha. National Discovery Channel. https://www.nationaldiscoverychannel. com/2014/10/amazing-history-of-deuki-pratha.html, Accessed: 03.03.2020.

Shahi, G. B. (2003). Socio-cultural study of Deuki system in Baitadi district. (Master's dissertation), Central department of Sociology/ Anthropology, Kirtipur, Kathmandu.

Shrestha, T. B. (2001). A new light to the Deo Dasi system: Various dimensions of Nepalese history. Kathmandu: Royal Nepal Academy

Stark, C. \& Rebecca W. (2004). Not for sale: Feminists resisting prostitution and pornography. North Melbourne, Victoria: Spinifex Press. https://ecommons.udayton.edu/phl_fac_pub/162, Accessed: 29.12.2020.

Subedi, R. (1991). About Deukis of Doti. Garima Year, 13(3). Lalitpur: Sajha Prakashan

Wanta, L. (1992.). Deuki and Badi. Cultural dispense of prostitution. The Voice of Child Worker, Issue 15116. Kathmandu, pp.15

Yatri, P.P.N. (1976). Mahakali anchal digdarshan. Biratnagar: Himali Sougat, pp. 127-130.

Yogi, A. G. (2012, Oct. 09). Women sacrificed to Gods struggle to rehabilitate, Deuki tradition wanes in Nepal. Washington D.C: Global Press Journal. https://globalpressjournal.com/asia/nepal/ women-sacrificed-to-gods-struggle-to-rehabilitate-deuki-traditionwanes-in-nepal/, Accessed: 02.012020. 